\title{
INTRAOPERATIVE PNEUMOTHORAX COMPLICATING TOTALLY EXTRAPERITONEAL INGUINAL HERNIA REPAIR
}

Charulatha $\mathrm{R}^{1}$, Balasubramanian $\mathrm{S}^{2}$, Yogeshwaran ${ }^{3}$

\section{HOW TO CITE THIS ARTICLE:}

Charulatha R, Balasubramanian S, Yogeshwaran. "Intraoperative Pneumothorax Complicating Totally Extraperitoneal Inguinal Hernia Repair". Journal of Evolution of Medical and Dental Sciences 2015; Vol. 4, Issue 60, July 27; Page: 10545-10548, DOI:10.14260/jemds/2015/1519

INTRODUCTION: Laparoscopic inguinal hernia repair compared with open procedure is associated with reduced recurrence rate and earlier return to work.[1,2] Though insufflation of carbon dioxide is limited to preperitoneal space, higher insufflation pressures and longer operative times have been associated with pneumothorax and pneumomediastinum even during totally extra peritoneal patchplasty (TEP).[3] We present a patient who developed pneumothorax due to inadvertent peritoneal tear during hernial sac dissection that resolved with conservative management in the postoperative period. This case report highlights the importance of peritoneal tear closure before proceeding with the rest of the procedure during extra peritoneal inguinal hernia repair.

KEYWORDS: Pneumothorax, Peritoneal tear, Laparoscopic inguinal hernia repair.

CASE REPORT: A twenty six year old previously healthy male weighing 55kgs was scheduled for left indirect inguinal hernia repair by laparoscopic totally extra peritoneal approach. His preoperative blood investigations and chest x-ray were within normal limits and was assessed as ASA 1 status.

Patient was wheeled into the OR and premedicated with Inj. Glycopyrrolate $0.2 \mathrm{mg}$ iv, Inj. Fentanyl 110mcg i.v, Inj. Lignocaine (2\%) 75mg i.v, Inj. Ondansetron 4mg i.v. General anesthesia was induced with Inj. Propofol 100mg i.v, Inj. Atracurium $30 \mathrm{mg}$ i.v. and trachea intubated with $8.0 \mathrm{~mm}$ ID ETT fixed at $21 \mathrm{~cm}$ at central incisors. Anesthesia was maintained with nitrous oxide $70 \%$, oxygen $30 \%$, Sevoflurane $1 \%$ and Inj. Atracurium as $5 \mathrm{mg}$ boluses at $30 \mathrm{~min}$ intervals. Ventilator settings were tidal volume $-8 \mathrm{ml} / \mathrm{kg}$, respiratory rate $10 / \mathrm{min}$, I: E ratio of 1:2. Baseline EtCO2 and mean airway pressures were $35 \mathrm{~mm} \mathrm{Hg}$ and $17 \mathrm{~cm}$ of $\mathrm{H} 20$ respectively.

Veress needle was introduced and carbon dioxide was insufflated at pressures of $10 \mathrm{~mm} \mathrm{Hg}$. Preperitoneal space was dissected and hernial sac was identified. During dissection of the hernia sac, inadvertent peritoneal tear occurred that resulted in reduction of preperitoneal working space. Hence insufflation pressures were raised to $15 \mathrm{mmHg}$ and a verees needle was inserted in left subcostal (Palmer's point) region. This restored the working space and further dissection was carried out. At this juncture EtCo2 was 38mm Hg and mean airway pressures remained at baseline levels.

Forty five minutes after the peritoneal tear, EtCO2 rose to $45 \mathrm{mmHg}$ and airway pressures to $25 \mathrm{~cm}$ of H20.There was a drop in SPO2 from $100 \%$ to $97 \%$. Air entry checked and was found to be reduced at right lung base. Suspecting right endobronchial intubation, ETT was pulled out and fixed at $19 \mathrm{~cm}$ at the level of central incisors. Subcutaneous emphysema was palpable on anterior chest wall extending up to clavicle. Thereafter there was a persistent rise in EtCo2 to $50 \mathrm{mmHg}$ and fall in SPO2 to 93\%. HR was 92/min and blood pressure was 150/100mmHg. Nitrous oxide was discontinued and patient was ventilated with $100 \%$ oxygen and Sevoflurane 1.5\%.This improved the oxygen saturation to $95 \%$. Then the patient was ventilated with $50 \%$ air oxygen mixture with tidal volume was reduced to $6 \mathrm{ml} / \mathrm{kg}$. 
Air entry was reduced at right lung base and infraclavicular region. Subcutaneous emphysema made percussion and auscultation over anterior chest wall difficult. On suspicion of pneumothorax, surgeon was asked to complete the procedure by open approach. Peritoneal tear was closed and mesh placed over myopectineal orifice. Release of carbon dioxide improved the hemodynamic parameters and there was drop in EtCO2 to normal values with SpO2 of 98\%.

Intraoperative chest $\mathrm{x}$-ray revealed right sided pneumothorax whose outer margin was less than $2 \mathrm{cms}$ from chest wall at the level of hilum. Possibility of capnothorax was high due to the peritoneal tear and raised insufflation pressures and prolonged duration of surgery. As capnothorax was known to resolve spontaneously in the post-operative period and as there were no signs of tension pneumothorax (bradycardia, hypotension, tracheal or mediastinal shift in chest x-ray), we decided to opt for conservative management. Neuromuscular block was reversed with Inj. Neostigmine $2.5 \mathrm{mg}$ and Inj. Glycopyrrolate $0.5 \mathrm{mg}$ i.v. With equipment for emergency ICD insertion ready by bedside, patient was extubated and placed on high flow oxygen of $10 \mathrm{~L} / \mathrm{min}$. His immediate post-operative oxygen saturation was $97 \%$.

Patient was observed in the recovery room and a chest x-ray taken 2 hrs. into the postoperative period showed radiological resolution of pneumothorax. Patient was briefed about the intraoperative complication and was comfortable except for mild pricking pain over right anterior chest wall. Inj. Diclofenac 75mg i.m. twice daily was prescribed for postoperative pain relief along with oral Paracetamol 650mg 8th hrly.

He was shifted to postoperative ICU and weaned off oxygen over 24 hours. Chest x-ray taken next day was normal and patient was discharged from the hospital after 2 days.

TIMELINE: Total duration of surgery 120 minutes.

Total duration of pneumoperitoneum 60 minutes.

DISCUSSION: Laparoscopic inguinal hernia repair consists of dissection of preperitoneal space, dissection of hernia sac, mesh placement and fixation. ${ }^{[4]}$ The preperitoneal space is insufflated with carbon dioxide at pressures of $8-10 \mathrm{mmHg}$. The initial insufflation pressures used in our patient were within the recommended levels. Insufflation of preperitoneal space with carbon dioxide does not cause significant changes in hemodynamics and blood gas composition at pressures of $10 \mathrm{mmHg}$ up to 90 minutes.[5]

Peritoneal tear can occur during dissection of the posterior rectus sheath or during dissection of hernia sac. Resulting pneumoperitoneum can have a pressure effect on anterior abdominal wall reducing working space for rest of the procedure. ${ }^{[4]}$ Insufflation pressures were raised in an attempt to restore the working space with placement of Veress needle in left subcostal point as a vent for the intraabdominal gas.

Early closure of the peritoneal tear with absorbable endoloop is advised since the escape of gas into intraabdominal cavity can affect the respiratory hemodynamics and can also precipitate post-operative ileus.

Larger tears may need multiple absorbable loops or intracorporeal sutures. A missed tear can occur in omental or intestinal herniation through the defect, with potential intestinal obstruction, incarceration, strangulation and delayed fistulisation.

Placement of Veress needle should only be secondary to closure of peritoneal tear and as the primary measure has not prevented the complications of pneumoperitoneum from occurring. 
The preperitoneal space is a dynamic space unlike the confined space of pneumoperitoneum. Hence the increased insufflation pressure from $10 \mathrm{mmHg}$ to $15 \mathrm{mmHg}$ resulted in subcutaneous emphysema with associated hypercarbia.[6]

Pneumothorax during laparoscopic surgery could be due to surgical or non-surgical causes.[7] Barotrauma, rupture of congenital bulla are also possibilities in our patient. Positive pressure ventilation with high pressures was not done and congenital bullae are not easily visualised in a chest $\mathrm{x}$-ray but require computed tomogram for diagnosis.

The possibility of capnothorax was high given the peritoneal tear and subsequently raised insufflation pressures. Hence the surgery was converted to open repair with closure of peritoneal tear and mesh placement. In the event of a capnothorax a tube thoracostomy is not mandatory and management is dictated by clinical circumstances because carbon dioxide is rapidly absorbed in the post-operative period. Harnessing on the physiological tolerance of our patient and increase in SPO2 after carbon dioxide disscontinuation, conservative management was adopted in this patient.

Chest $\mathrm{X}$ rays in supine position have limited sensitivity for detection of pneumothorax. $\mathrm{M}$ mode ultrasound can be used to confirm the diagnosis and to assess lung expansion in the postoperative period.[8] In case of capnothorax PEEP can be carefully applied which will help in quicker resolution of pneumothorax.[9]

We are seriously flawed in not doing a fibreoptic bronchoscopy to rule out endo bronchial intubation or mucous plug and ABG to assess the severity of acidosis. Review of literature shows they are valuable tools in management of similar case scenarios.

CONCLUSION: Though the incidence of pneumothorax during laprascopic surgery (Intra peritonal or extra peritoneal approach) is small, 1.9\%, this serious complication should always be borne in mind. Peritoneal tears of any degree during TEP should be closed without delay and when complications due to pneumoperitoneum occur, interruption of procedure and release of carbondioxide or in case of hemodynamic instability, conversion to open procedure might be necessary.

\section{REFERENCES:}

1. Memon M A, Cooper N J, Memon Be Meta-analysis of randomised clinical trials comparing open and laparoscopic inguinal hernia repair. Br J Surg 2003: 90: 1479-1492.

2. McCormack K, Wake B, Perez J, Fraser C, Cook J, McIntosh E, et al. Laparoscopic surgery for inguinal hernia repair: systematic review of effectiveness and economic evaluation. Health Technol Assess 2005; 9(14).

3. Murdock CM. ${ }^{1}$, Wolff AJ, Van Geem T Risk factors for hypercarbia, subcutaneous emphysema, pneumothorax, and pneumomediastinum during laparoscopy. Obstet Gynecol. 2000 May; 95(5):704-9.

4. Davide Lomanto and Avinash N. Katara Managing intra-operative complications during totally extraperitoneal repair of inguinal hernia J Minim Access Surg. Sep 2006; 2(3): 165-170.

5. CPT Michael W. Blaney, MD, William C. Calton, MD, and LTC James H. North, Jr, MD The Effects of Preperitoneal Carbon Dioxide Insufflation on Cardiopulmonary Function in Pigs JSLS. 1999 JanMar; 3(1): 49-55.

6. Douglas E. Ott, MD, MBA Subcutaneous Emphysema-Beyond the Pneumoperitoneum JSLS. 2014 Jan-Mar; 18(1): 1-7. 


\section{CASE REPORT}

7. Mehran A1 , Brasesco O, De Velasco E, Szomstein S, Rosenthal R. Intra-operative pneumothorax complicating laparoscopic Roux-en-Y gastric bypass. Obes Surg. 2004 Jan; 14(1):124-8.

8. Oveland NP. ${ }^{1}$, Lossius HM, Wemmelund K, Stokkeland PJ, Knudsen L, Sloth E.

Using thoracic ultrasonography to accurately assess pneumothorax progression during positive pressure ventilation: a comparison with CT scanning. CHEST 2013 Feb 1; 143(2):415-22.

9. Hye Young Kim. ${ }^{1}$, Tae-Yop Kim. ${ }^{2}$, Kyu Chang Lee. ${ }^{1}$, Myeong Jong Lee. ${ }^{1}$, Seong-Hyop Kim. ${ }^{2}$, Jong Min Bahn, et al Pneumothorax during laparoscopic totally extraperitoneal inguinal hernia repair -A case report Korean J Anesthesiol. May 2010; 58(5): 490-494.

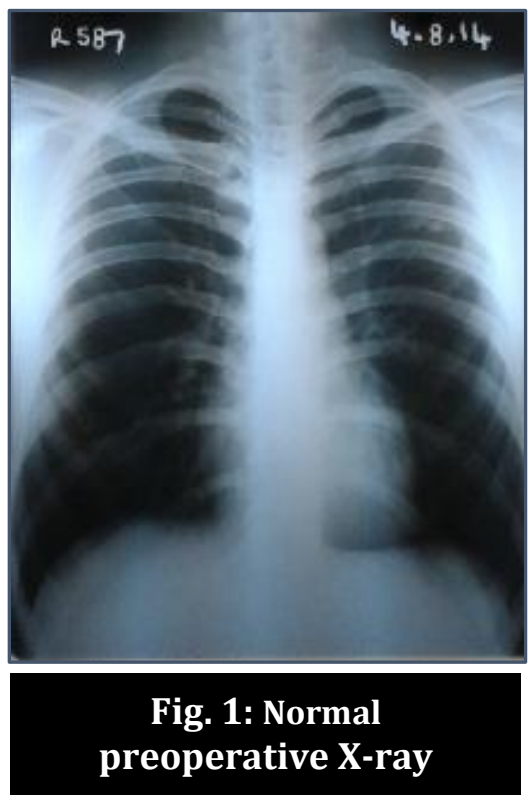

\section{AUTHORS:}

1. Charulatha R.

2. Balasubramanian S.

3. Yogeshwaran

\section{PARTICULARS OF CONTRIBUTORS:}

1. Assistant Professor, Department of Anaesthesia, Sri Manakula Vinayakar Medical College and Hospital.

2. Associate Professor, Department of Anaesthesia, Sri Manakula Vinayakar Medical College and Hospital.

\section{FINANCIAL OR OTHER} COMPETING INTERESTS: None

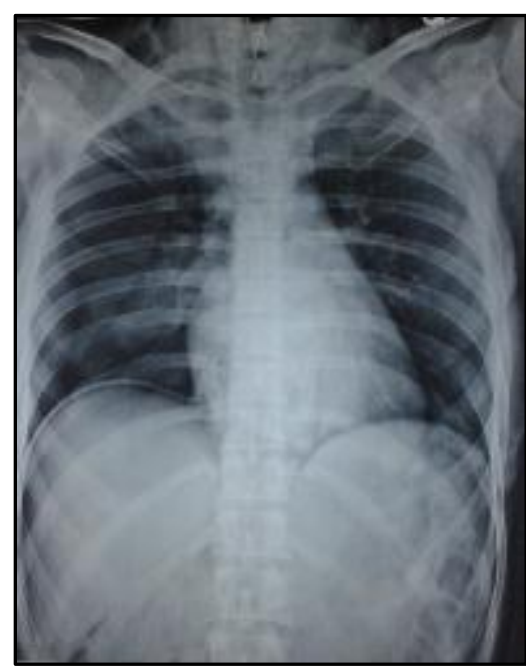

Fig. 2: Post-Operative X-ray Showing Pneumothorax

3. Post Graduate, Department of Anaesthesia, Sri Manakula Vinayakar Medical College and Hospital.

\section{NAME ADDRESS EMAIL ID OF THE} CORRESPONDING AUTHOR:

Dr. Charulatha R,

27, Maria Susai Nagar, Cuddalore-607001.

Email: ravindrancharulatha@gmail.com

Date of Submission: 01/07/2015. Date of Peer Review: 02/07/2015. Date of Acceptance: 20/07/2015. Date of Publishing: 27/07/2015. 